\title{
The glass is half full
}

\author{
Kevin J. Koomalsingh, MD, and Nahush A. Mokadam, MD
}

\footnotetext{
From the Division of Cardiothoracic Surgery, University of Washington, Seattle, Wash.

Disclosures: Dr Mokadam is a consultant to Abbott and Medtronic and an investigator for Abbott, Medtronic, and SynCardia. Koomalsingh has nothing to disclose with regard to commercial support.

Received for publication Sept 21, 2017; accepted for publication Sept 22, 2017; available ahead of print Oct 19, 2017.

Address for reprints: Nahush A. Mokadam, MD, LeRoss Endowed Professor in Cardiovascular Surgery, Division of Cardiothoracic Surgery, University of Washington, 1959 NE Pacific St, Box 356310, Seattle, WA 98195 (E-mail: mokadamn@uw.edu).

J Thorac Cardiovasc Surg 2018;155:822-3

$0022-5223 / \$ 36.00$

Copyright $(2017$ by The American Association for Thoracic Surgery

https://doi.org/10.1016/j.jtcvs.2017.09.103
}

The French physician Nostradamus became famous by writing The Prophecies, which publicized his visions gained from meditation. His works are often cited and believed by those who read them. Subject to interpretation, his quatrains remain a source of entertainment, vision, and fear for many. ${ }^{1}$ In this issue of The Journal of Thoracic and Cardiovascular Surgery, Moffatt-Bruce and colleagues ${ }^{2}$ offer a provocative and dire vision for our specialty compared with predictions before it, which emphasized the decline of cardiothoracic surgery. This article depicts a harrowing picture of physician overload and burnout as a result of the aging population and an inadequately prepared workforce. From a number of well-regarded projections, Moffatt-Bruce and colleagues ${ }^{2}$ predict an average caseload increase of $120 \%$ per surgeon by 2035 . Other groups have made similar projections. Etzioni and colleagues ${ }^{3}$ anticipate that the demand for valvular and coronary procedures will increase about $50 \%$ in the next 10 to 15 years.

During the past 2 decades, we have witnessed a technologic revolution in cardiothoracic surgery. Within the adult cardiac space, transcatheter valves and repair techniques, miniaturized ventricular support devices, endovascular aortic surgery, and hybrid cardiac surgery have all contributed to a rejuvenated frontier. Complex interventions may now be safely completed in patients with higher risk profiles, often without a sternotomy or cardiopulmonary bypass. Landmark surgical clinical trials, along with their medical counterparts, continually populate the headlines of The New England Journal of Medicine, JAMA, and The Lancet. Coronary revascularization, which at one time had the bleakest of futures, has reclaimed credibility with total arterial revascularization. In general thoracic surgery, we have seen new invigoration in lung cancer screening. ${ }^{4} \mathrm{We}$ have also seen advances in tumor biology facilitating personalized medicine and advances in chemoradiation allowing previously unresectable tumors to reenter the surgical realm. Similarly, in congenital heart surgery, catheter-based technologies are providing alternate treatment strategies, powerful imaging tools and 3-dimensional printing are increasingly being used for surgical planning,

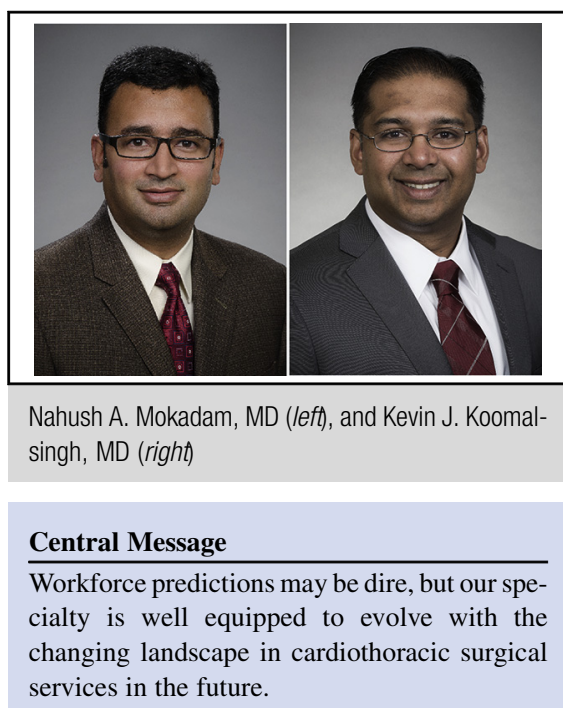

See Article page 824 and the field of regenerative medicine is vying for bioengineered replacement tissue. ${ }^{5}$

To be complete, some of these disruptive technologies may also reduce the clinical need for surgical specialists. As transcatheter valves continue to decrease their profiles, the need for surgical partnership may decrease, or even disappear. The novel uses of immunotherapy may create a vacuum in resective therapy for thoracic malignancies. New percutaneous techniques may offer children with congenital heart disease alternatives to the traditional approaches. The projected increase in surgical volume may not, in fact, come to fruition.

We have already witnessed the value of a multidisciplinary approach to cancer care and solid-organ transplantation. The extension to cardiac care and the implementation of a heart team is the burgeoning criterion standard. With the integration of care among various specialists, patients will receive individualized therapy in a best-practice environment. Some may view the evolving clinical landscape with trepidation. We are more optimistic. Cardiothoracic surgeons are reentering a golden era with contemporary tools, a broadening skill set, and a multidisciplinary approach to complex patient care. New recruits will be magnetized to the field. Carpe diem. It is our opportunity and our responsibility to accept the challenge.

\section{References}

1. Biography.com. Nostradamus: Scientist (c. 1503-1566). Available at: www. biography.com/people/nostradamus-9425407. Accessed September 12, 2017. 
2. Moffatt-Bruce S, Crestanello J, Way DP, Williams TE. Providing cardiothoracic services in 2035: signs of trouble ahead. J Thorac Cardiovasc Surg. 2018;155: 824-9.

3. Etzioni DA, Starnes VA. The epidemiology and economics of cardiothoracic surgery in the elderly. In: Katlic MR, ed. Cardiothoracic Surgery in the Elderly. New York: Springer Science + Business Media; 2011:5-24.
4. Wood DE, Eapen GA, Ettinger DS, Hou L, Jackman D, Kazerooni E, et al. Lung cancer screening. J Natl Compr Cancer Netw. 2012;10: 240-65.

5. Vukicevic M, Mosadegh B, Min JK, Little SH. Cardiac 3D printing and its future directions. JACC Cardiovasc Imaging. 2017;10:171-84. 